\title{
PENGARUH PENILAIAN ETIKA TERHADAP PERILAKU MAHASISWA FAKULTAS TARBIYAH DAN KEGURUAN
}

\author{
Dwi Putri Musdansi ${ }^{1}$, Rosa Murwindra ${ }^{2}$, Helbi Akbar \\ ${ }^{1}$ Fakultas Tarbiyah dan Keguruan, Universitas Islam Kuantan Singingi \\ Email dwipu3musdansi.uniks@gmail.com \\ ${ }^{2}$ Fakultas Tarbiyah dan Keguruan,Universitas Islam Kuantan Singingi \\ Email rosamurwindra@gmail.com \\ ${ }^{3}$ Fakultas Tarbiyah dan Keguruan,Universitas Islam Kuantan Singingi
}

\begin{abstract}
This research is a quantitative study that aims to analyze the effect of ethical judgment on student behavior at the Kuantan Singingi Islamic University (UNIKS). The population used was students of the Tarbiyah and Teaching Faculty (FTK) with the sampling technique. Random sampling used SPSS. Data collection techniques use secondary data sources and pimer, for independent variables using secondary data sources by directly requesting the FTK UNIKS archive center, while the dependent variable uses primary data sources obtained directly from the original source through the Behavior scale. The test statistic needed to test the hypothesis is the correlation coefficient between the test score as a predictor and the score of a criterion. The interpretation of the analysis results in predictive studies is based on the betha index $(\beta)$ or the b score in the regression model obtained. From the results of the study it was concluded that there was an effect of ethical judgment on the behavior of FTK UNIKS students with sig $=0.00$ and $F=50.524, Y=31.5+$ $0.645 X$
\end{abstract}

Keywords: Influence, Ethical Assessment, Behavior, FTK Students

\section{PENDAHULUAN}

Di era globlalisasi saat ini, banyak pengaruh-pengaruh luar yang menyebabkan dekadensi moral. Dekadensi moral disebabkan berbagai faktor, diantaranya: kemajuan teknologi, memudarnya kualitas keimanan, pengaruh lingkungan, hilangnya kejujuran, hilangnya rasa tanggung jawab, tidak berpikir jauh ke depan, rendahnya disiplin.

Seorang pakar pendidikan karakter asal Amerika Thomas Lickona seperti dikutip oleh Anita Syaharudin mengungkapkan bahwa sebuah bangsa sedang menuju jurang kehancuran, jika memiliki sepuluh tanda-tanda zaman, yaitu: (1) meningkatnya kenakalan dikalangan remaja, (2) membudaya ketidakjujuran (3) sikap fanatik terhadap kelompok, (4) rendahnya rasa hormat kepada orang tua dan guru (5) semakin kaburnya moral baik dan buruk, (6) penggunaan bahasa yang memburuk, (7) meningkatnya perilaku yang merusak diri seperti penggunaan narkoba, alkohol dan seks bebas, (8) rendahnya tanggung jawab sebagai individu dan sebagai warga negara, (9) menurunnya etos kerja, (10) dan adanya rasa saling curiga serta kurangnya kepedulian diantara sesama.

Beberapa kejadian berikut ini setidaknya menunjukan bahwa moral anak bangsa telah menunjukkan kemerosotan. (1) Seorang pelajar Kelas X SMA Negeri di Kubu Raya, EY (20), tega menganiaya guru Sosiologinya, PR. Akibatnya, perempuan berusia 33 tahun itu, mengalami luka di kening (sumber:Tribun kebunraya.com, 20 juni 2017). (2) Tindak pemukulan yang dilakukan oleh seorang alumni terhadap guru, hari ini siswa dan guru di sekolah SMP Negeri 14 Koya 
Koso Distrik Muara Tami Kota Jayapura (sumber : okezone.com; 11 oktober 2017). (3) Pada hari Kamis, 2 November 2017, pukul 11.30 WIB, di salah satu SMK di Kota Pontianak, telah terjadi kasus perkelahian sesama pelajar, teman sekelas, di ruang kelas, pada pergantian jam pelajaran. (sumber: sindonews.com)

Tidak hanya itu, kalangan mahasiswapun juga pernah melakukan tindak pidana terhadap dosennya. Seperti kasus Nur Ain Lubis (63), dosen Fakultas Keguruan dan Ilmu Pendidikan (FKIP) Universitas Muhammadiyah Sumatera Utara (UMSU) tewas setelah ditikam mahasiswanya, Roymardo Sah Siregar (20), pada Senin (2/5/2016) sekitar pukul 15.00 WIB (sumber: Kompas.com, medan)

Kemerosotan moral berarti merosotnya etika dan akhlak.Tidak bermoral berarti tidak memiliki etika yang baik. Ardy (2015:3) mengungkapkan Etika dan moral memiliki hubungan yang saling berkaitan dan tidak bisa dipisahkan satu sama lainnya, jika berbicara mengenai etika, maka pada saat bersamaan kita juga membicarakan mengenai moral. Dalam KBBI, etika adalah Ilmu tentang apa yang baik dan apa yang buruk dan tentang hak dan kewajiban (moral). Gazalba (2012) mengungkapkan etika adalah ilmu tentang moral yang mengkaji mengenai prinsip-prinsip dan kaedah moral mengenai tindakan dan kelakuan.

Jadi jelaslah bahwa etika berbicara mengenai moral. Merosotnya moral, menunjukkan etika yang tidak baik, sehingga perlu dilakukan pencegahan dari sedini mungkin agar moralitas bangsa menjadi lebih baik. Seperti yang diungkapkan oleh Direktur Jenderal Pendidikan Anak Usia Dini dan Pendidikan Masyarakat (Dirjen PAUD dan Dikmas) Harris Iskandar, 23 September 2016 bahwa pentingnya menumbuhkan berbagai karakter moral. Karakter-karakter tersebut adalah karakter takwa terhadap Tuhan, karakter cinta tanah air, karakter hormat kepada lingkungan, diri sendiri, dan sesama.

Fakultas Tarbiyah dan Keguruan (FTK) Universitas Islam Kuantan Singingi (UNIKS) memasukkan komponen penilaian etika sebagai salah satu komponen evaluasi hasil belajar mahasiswa.

Mahasiswa adalah peserta didik pada jenjang Pendidikan Tinggi (UU RI Nomor 12 Tahun 2012 Tentang pendidikan tinggi). Hasil belajar merupakan perubahan tingkah laku setelah melaui proses belajar mengajar (Majid: 2014). Tingkah laku dalam pengertian luas mencakup bidang kognitif, afektif, dan psikomotorik. Woordworth mengemukakan hasil belajar adalah kemampuan aktual yang diukur secara langsung. Hasil belajar merupakan pucak dari proses belajar. Hasil belajar dapat diketahui setelah dilakukan pengukuran dan penilaian. Pengukuran dan penilaian hasil belajar dilakukan dengan menggunakan tes hasil belajar, terutama belajar kognitif yang berkenaan dengan penguasaan bahan pengajaran sesuai dengan tujuan pendidikan dan pengajaran.

Sudjana (2004) mengemukakan bahwa penilaian hasil belajar adalah proses pemberian nilai terhadap hasil-hasil belajar yang dicapai peserta didik dengan kriteria tertentu. Hal ini mengisyaratkan obyek yang dinilainya adalah hasil belajar peserta didik. Hasil pengukuran belajar inilah yang kemudian akan mengetahui seberapa jauh tujuan pendidikan dan pengajaran yang telah dicapai.

Menurut Majid (2014) penialaian proses pengajaran terdiri dari kemampuan peserta didik, minat, perhatian, motivasi belajar peserta didik, kebiasaan belajar, pengetahuan awal, dan karakteristik peserta didik. Keberhasilan belajar atau hasil belajar dioperasionalkan dalam bentuk indikatorindikator berupa nilai rapor, indeks prestasi, angka kelulusan, prediksi keberhasilan, dan sebagainya (azwar, 1996)

Dengan demikian jelaslah bahwa hasil belajar merupakan obyek dari penilaian hasil belajar. Di UNIKS, hasil belajar mahasiswa setiap semester ditunjukkan dengan Indeks Prestasi Mahasiswa yang umumnya menggunakan indeks prestasi dilambangkan dengan angka 0 sampai 4 sebagai indikator prestasi hasil belajar mahasiswa. Berikut 
ketentuan konversi nilai ke bentuk huruf dan pembobotan di UNIKS.

Tabel 1 Ketentuan Konversi Nilai

\begin{tabular}{|c|c|c|c|}
\hline No & $\begin{array}{c}\text { Nilai } \\
\text { Angka }\end{array}$ & $\begin{array}{c}\text { Nilai } \\
\text { Huruf }\end{array}$ & Bobot \\
\hline 1 & $80-100$ & A & 4 \\
\hline 2 & $70-79$ & B & 3 \\
\hline 3 & $56-59$ & C & 2 \\
\hline 4 & $45-55$ & D & 1 \\
\hline 5 & $<44$ & E & 0 \\
\hline
\end{tabular}

Nilai diperoleh tentu setelah dilakukan penilaian hasil belajar mahasiswa. Adapun komponen penilaian mencakup:
a. UAS
$:(20 \%-40 \%)$
b. UTS
$:(20 \%-30 \%)$
c. Tugas
$: 15 \%-30 \%)$
d. Akhlak /etika : $(0-15 \%)$
e. Kehadiran : $(0-15 \%)$

Jumlah persentase nilai keseluruhan harus $100 \%$.

Dari Penjelasan diatas terlihat jelas bahwasannya etika dimasukkan dalam evalusi hasil belajar mahasiswa namun, tidak dapat diungkapkan secara jelas, apakah komponen penilaian etika tesebut berpengaruh terhadap perilaku mahasiswa, sehingga dalam penelitian ini akan dilakukan penelitian tentang menganalisa pengaruh penilaian etika terhdap perilaku mahasiswa.

\section{METODE PENELITIAN}

Model penelitian yang digunakan adalah penelitian Kuantitatif, dengan menemukan koefisien korelasi dan persamaan regresinya antara variabel bebas (Skor Penilaian Etika mahasiswa) dan variabel terikat (perilaku Mahasiswa). Penelitian ini berlokasi di Fakultas Tarbiyah dan Keguruan Universitas Islam Kuantan Singingi. Sampel dipilih dengan Random sampling menggunakan SPSS. Sampel dalam penelitian ini sebanyak 30 orang, 20 berjenis kelamin perempuan dan 10 orang berjenis kelamin laki-laki. Sampel itulah yang kemudian diamati melalui lembar checklist observasi.

Sumber data dapat berupa data primer dan data skunder. Data primer adalah sumber data yang diperoleh langsung dari sumber asli. Sedangkan sumber data sekunder merupakan sumber data penelitian yang diperoleh melalui media perantara atau secara tidak langsung yang berupa buku catatan, bukti yang telah ada, atau arsip, baik dipublikasikan maupun yang tidak dipublikasikan secara umum.

Dalam penelitian ini menggunakan sumber data sekunder dan pimer, sehingga teknik pengumpulan data untuk variabel bebas menggunakan sumber data sekunder dengan langsung meminta ke pusat arsip Fakultas Tarbiyah dan Keguruan Universitas Islam Kuantan Singingi, sedangkan variabel terikat menggunakan sumber data primer yang diperoleh langsung dari sumber asli, dimana pengukuran melalui lembar checklist observasi dengan menggunakan responden yang telah dirandom sebelumnya sehingga responden tersebut yang diamati hingga 3 kali pengamatan. Dan selanjutnya jumlah dari observasi masing-masing individu dirata-ratakan. Rata-rata itulah kemudian yang dikorelasikan dengan data Etika yang sudah ada sebelumnya.

Analisis data dilakukan dengan SPSS.20 dengan menentukan besar koefisien korelasi dan persamaan regresi linear sebagai persamaan prediktif.

\section{HASIL DAN PEMBAHASAN}

Penelitian ini menggunakan sampel sebanyak 30 responden. Pengukuran variabel terikat menggunakan lembar checlist observasi yang berjumlah sebanyak 15 butir. Adapun hasil penelitian dapat dilihat dari tabel berikut ini:

\section{Tabel 1. Deskripsi Data}

\begin{tabular}{|l|r|r|r|}
\hline \multicolumn{4}{|c|}{ Descriptive Statistics } \\
\hline & Mean & $\begin{array}{c}\text { Std. } \\
\text { Deviation }\end{array}$ & N \\
\hline Skor_Prilaku & 83.00 & 6.898 & 30 \\
Skor_Etika & 79.87 & 8.581 & 30 \\
\hline
\end{tabular}


Tabel.2 Koefisien Korelasi antara dua variabel

\begin{tabular}{|ll|r|r|}
\hline \multicolumn{1}{|c|}{ Correlations } \\
\hline & \multicolumn{1}{c|}{$\begin{array}{c}\text { Skor_ } \\
\text { Prilaku }\end{array}$} & $\begin{array}{r}\text { Skor_- } \\
\text { Etika }\end{array}$ \\
\hline Pearson & Skor_Prilaku & 1.000 & .802 \\
Correlation & Skor_Etika & .802 & 1.000 \\
Sig. (1- & Skor_Prilaku &. & .000 \\
tailed) & Skor_Etika & .000 &. \\
N & Skor_Prilaku & 30 & 30 \\
& Skor_Etika & 30 & 30 \\
\hline
\end{tabular}

\section{Variables Entered/Removed $^{\mathrm{a}}$}

\begin{tabular}{|l|c|c|l|}
\hline $\begin{array}{l}\text { Mode } \\
1\end{array}$ & $\begin{array}{c}\text { Variables } \\
\text { Entered }\end{array}$ & $\begin{array}{c}\text { Variables } \\
\text { Removed }\end{array}$ & Method \\
\hline 1 & Skor_Etika $^{\mathrm{D}}$ & & Enter \\
\hline
\end{tabular}

a. Dependent Variable: Skor_Prilaku

b. All requested variables entered.

1. Pengujian Hipotesis

a. Rumusan Hipotesis

* Hipotesis kerja atau hipotesis penelitian

$\mathrm{H}_{0}$ : tidak terdapat pengaruh penilaian etika terhadap perilaku mahasiswa FTK

$\mathrm{H}_{1}$ : terdapat pengaruh penilaian etika terhadap perilaku mahasiswa FTK

* Hipotesis statistik

$$
\begin{aligned}
& \mathrm{H}_{0}: \beta=0 \\
& \mathrm{H}_{1}: \beta \neq 0
\end{aligned}
$$

b. Taraf signifikansi $\alpha=5 \%$

c. Hasil Pengolahan Data dengan SPSS Model Summary ${ }^{b}$

\begin{tabular}{|l|c|c|c|c|}
\hline Model & $\mathrm{R}$ & $\begin{array}{c}\mathrm{R} \\
\text { Squar } \\
\mathrm{e}\end{array}$ & $\begin{array}{c}\text { Adjusted } \\
\mathrm{R} \\
\text { Square }\end{array}$ & $\begin{array}{c}\text { Std. Error } \\
\text { of the } \\
\text { Estimate }\end{array}$ \\
\hline 1 & $.802^{\mathrm{a}}$ & .643 & .631 & 4.192 \\
\hline
\end{tabular}

a. Predictors: (Constant), Skor Etika

b. Dependent Variable: Skor_Prilaku

\section{ANOVA $^{\mathrm{a}}$}

\begin{tabular}{|r|r|r|c|c|c|}
\hline Model & $\begin{array}{c}\text { Sum of } \\
\text { Squares }\end{array}$ & df & $\begin{array}{c}\text { Mean } \\
\text { Square }\end{array}$ & $F$ & Sig. \\
\hline $\begin{array}{l}\text { Regr } \\
\text { essio }\end{array}$ & 887.923 & 1 & 887.923 & 50.524 & $\begin{array}{r}.000 \\
\mathrm{~b}\end{array}$ \\
$1 \begin{array}{c}\mathrm{n} \\
\text { Resi } \\
\text { dual }\end{array}$ & 492.077 & 28 & 17.574 & & \\
\hline
\end{tabular}

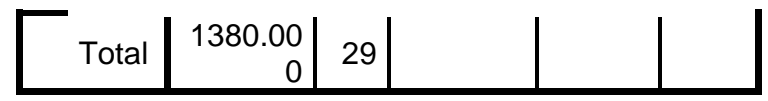

a. Dependent Variable: Skor_Prilaku

b. Predictors: (Constant), Skor_Etika

d. Kriteria Pengujian dan Keputusan $\mathrm{H}_{0}$ ditolak jika $\mathrm{P}$ value $\leq 0,05$ $\mathrm{H}_{1}$ diterima jika $\mathrm{P}$ value $>0,05$ $P$ value $=$ sig $=0,00<0,05$, maka $\mathrm{H}_{0}$ ditolak

e. Kesimpulan

Ada Pengaruh Penilaian Etika terhadap prilaku mahasiswa FTK UNIKS

2. Persamaan Regresi Coefficients $^{\mathrm{a}}$

\begin{tabular}{|l|r|r|r|c|c|}
\hline Model & \multicolumn{2}{|c|}{$\begin{array}{c}\text { Unstandardized } \\
\text { Coefficients }\end{array}$} & $\begin{array}{c}\text { Stan } \\
\text { dardi } \\
\text { zed } \\
\text { Coef } \\
\text { ficien } \\
\text { ts }\end{array}$ & $\mathrm{t}$ & Sig. \\
\cline { 2 - 5 } & $\mathrm{B}$ & $\begin{array}{c}\text { Std. } \\
\text { Error }\end{array}$ & Beta & & \\
\hline $\begin{array}{c}\text { (Const } \\
\text { ant) } \\
\text { Skor_- } \\
\text { Etika }\end{array}$ & 31.500 & 7.286 & & 4.324 & .000 \\
\hline
\end{tabular}

a. Dependent Variable: Skor_Prilaku

\section{Persamaan regresi $Y=31,5+0,645 X$}

Residuals Statistics ${ }^{a}$

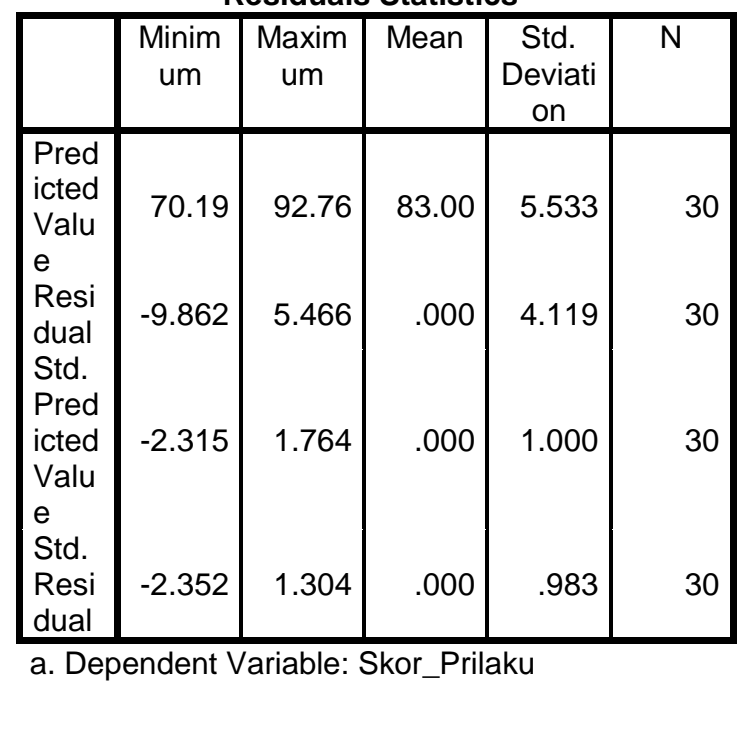




\section{A. Pembahasan}

Dari penelitian disimpulkan bahwa ada pengaruh penilaian etika terhadap perilaku mahasiswa FTK dengan sig $=0,00$ dan $\mathrm{R}^{2}=0.643$ yang menunjukkan bahwa $64,3 \%$ dari Prilaku dapat dijelaskan oleh perubahan dalam variabel etika. Selanjutnya Persamaan regresi yang terbentuk yaitu $\mathbf{Y}=\mathbf{3 1 , 5}+\mathbf{0 , 6 4 5 X}$ yang berarti perubahan satu satuan pada $X$ akan menaikkan nilai Y sebesar 0,645. Dari hasil tersebut dapat ditegaskan bahwasannya skor hasil penilaian etika dapat memprediksikan prilaku seseorang. Artinya dari skor tersebut selanjutnya kita dapat memprediksikan apakah peserta didik tersebut memiliki etika baik atau tidak. Tentu hal tersebut juga dipengaruhi oleh proses yang dilaluinya, sehingga semua sangat bergantung pada skor etika yang didapatka serta dengan adanya hasil ini tentu juga mengindikasikan bahwasanya penilaian etika yang ada di FTK dapat dijadikan acuan. Hal ini sejalan dengan pendapat Smith dalam Wati dan Bambang (2016) pendidikan etika bagi seseorang sangat dibutuhkan sehingga memberikan pemahaman konsep etika yang lebih jelas.

Terdapat empat alasan mengapa mempelajari etika sangat penting: 1) etika memandu manusia dalam memilih berbagai keputusan yang dihadapi dalam pendidikan; 2) etika merupakan pola perilaku yang didasarkan pada kesepakatan nilai-nilai sehingga kehidupan yang harmonis tercapai; 3) dinamika dalam kehidupan manusia menyebabkan perubahan nilainilai moral sehingga perlu dilakukan analisa dan ditinjau ulang; 4) etika mendorong tumbuhnya naluri moralitas dan memahami manusia untuk sama-sama mencari, menemukan dan memahami manusia untuk sama-sama mencari, menemukan dan menerapkan nilai-nilai hidup yang hakiki.

\section{SIMPULAN}

Penelitian ini disimpulkan bahwa ada pengaruh penilaian etika terhadap prilaku mahasiswa FTK dengan sig=0,05 dan $\mathrm{F}=$ $50,524, \mathbf{Y}=\mathbf{3 1 , 5}+\mathbf{0 , 6 4 5} \mathrm{X}$

\section{REFERENSI}

Ali, Mohammad. 2011. Melakukan Riset Prilaku dan Sosial. Pustaka Cendikia Utama: Bandung

Arikunto, Suharsimi. 2004. Dasar-dasar Evaluasi Pendidikan. Bumi Aksara: Jakarta

Azwar, Saifuddin. 1996. Tes Prestasi. Pustaka Pelajar: Yogyakarta.

Azwar, Saifuddin. 2012. Reliabilitas dan Validitas. Pustaka Pelajar: Yogyakarta.

Badiran, Muhammad. 2011. Pembelajaran dalam prespektif Etika dan karakter pendidikan, dalam praktik etika pendidikan diseluruh wilayah NKRI. Alfabeta: Bandung

Calongesi, J. S. 1995. Merancang Tes Untuk Menilai Prestasi Peserta Didik. ITB: Bandung

Dirman. 2014. Penialaian dan Evaluasi. Jakarta : Rhineka Cipta

Fauzan. 2012. Pengaruh Religiusitas Etika

Kerja Islami Terhadap Motivasi Kerja. Jurnal Online: Modernisasi, Volume 8, Nomor 3.

Gazalba, Sidi 2002. Sistematika Filsafat: Pengantar kepada teori nilai. Bulan Bintang: Jakarta.

Majid, Abdul. 2014. Penialaian Autentik Proses dan Hasil Belajar. PT. Rosdakarya: Bandung.

Muchlis. 2011. Pembelajaran dan penilaian berorientasi nilai (akhlak) dan dampaknya terhadap perilaku mahasiswa STAIN Pemakasan. Jurnal Online: Nuansa, Volume 8, Nomor 1. 
Permata S .2012. Pengaruh muatan etika pendidikan Akuntansi terhadap presepsi etika mahasiswa. Online Jurnal: Jurnal Akuntansi

Multiparadigman. Volume 3; Nomor 3

Rasyid, Harun, dkk. 2007. Penilaian Hasil Belajar. CV Wacana Prima :Bandung

Sudjana, Nana. 2004. Penilaian Hasil Proses Pembelajaran. PT. Remaja Rosda Karya: Bandung

Undang- Undang RI Nomor 12 Tahun 2012 Tentang Pendidikan Tinggi.

Undang-Undang Republik Indonesia Nomor 20 tahun 2003 Tentang Sistem Pendidikan Nasional

Zainul, Asmawi dan Nasution. (2001). Penilaian Hasil Belajar. Jakarta: Dirjen Dikti. https://www.kemdikbud.go.id/main/blog/20 16/09/tumbuhkan-karakter-moral-dankarakter-kinerja-lewat-kemah-budaya (dilihat pada 8-11-17)

https://news.okezone.com/read/2017/10/11/ 65/1793437/waduh-alumni-pukulguru-siswa-smp-di-jayapura-terpaksadiliburkan?utm_source $=$ news\&utm_m edium=news_box\&utm_campaign=bre aking0

https://daerah.sindonews.com/read/125 5388/174/penjelasan-soal-videopemukulan-brutal-siswa-di-salah-satu-smkkota-pontianak-1510064957.

Wati, Mirna dan Bambang. 2016. Pengaruh Pendidikan Etika Bisnis terhadap presepsi etis mahasiswa akuntansi. Jurnal Economica. Vol.12.No.2 